\title{
Internal health locus of control as a predictor of pain reduction in multidisciplinary inpatient treatment for chronic pain: a retrospective study
}

This article was published in the following Dove Press journal: Journal of Pain Research

\author{
Elian Zuercher- \\ Huerlimann ${ }^{1,2}$ \\ Julian A Stewart ${ }^{1,3}$ \\ Niklaus Egloff ${ }^{\prime}$ \\ Roland von Känel ${ }^{4}$ \\ Martina Studer ${ }^{1,3}$ \\ Martin grosse Holtforth ${ }^{1,3}$ \\ 'Division of Psychosomatic Medicine, \\ Department of Neurology, Inselspital, Bern \\ University Hospital, Bern, Switzerland; \\ ${ }^{2}$ Department of Psychology, University of \\ Zurich, Zurich, Switzerland; ${ }^{3}$ Department \\ of Psychology, University of Bern, Bern, \\ Switzerland; ${ }^{4}$ Department of Consultation- \\ Liaison Psychiatry and Psychosomatic \\ Medicine, University Hospital Zurich, \\ Zurich, Switzerland
}

Purpose: Chronic pain is a major health concern and its treatment requires physiological as well as psychological interventions. This study investigates the predictive value of health locus of control (HLOC) in pain intensity in chronic pain patients in an inpatient treatment setting.

Patients and methods: Data of 225 patients with a chronic pain condition were collected in a psychosomatic university clinic in Switzerland. Self-report assessment tools were used to measure pain intensity pre- and posttreatment and with a questionnaire dimensions of the HLOC were captured. Using hierarchic linear regression analysis, the predictive value of HLOC was investigated.

Results: A higher internal HLOC at pre-treatment was associated with a greater reduction in pain intensity from pre- to posttreatment $(\beta=-0.151, p<0.05)$. For social-external and fatalistic-external HLOC no significant effects were observed.

Conclusion: Internal HLOC showed predictive value regarding the reduction in pain intensity in a multidisciplinary inpatient treatment for chronic pain, whereas social-external and fatalistic-external HLOC did not. Early interventions to strengthen internal beliefs of health control may be a promising component in multidisciplinary inpatient treatment for patients with chronic pain.

Keywords: chronic pain, health attribution, pain relief, inpatient treatment, self-management

\section{Plain language Summary}

Suffering from chronic pain is a widely spread health problem, and has a large impact on physical functioning and quality of life. Multidisciplinary therapy represents an individual combination of physical therapy, medication, surgical treatment, relaxation therapy as well as psychological interventions and psychotherapy.

Some patients do not satisfyingly profit from their treatments, so that the search for outcome predictors becomes particularly important. Earlier studies have found evidence that physical and mental health can be influenced by a person's beliefs about what is affecting and controlling his or her health. These beliefs can be internal, when patients see themselves in control, or external, when they feel medical experts or luck and fate being in control.

In our study with 225 inpatients in multidisciplinary therapy for chronic pain, we were interested in how the patients' control beliefs impact their pain intensity after treatment. We found a positive effect of higher internal control beliefs on reduction in pain intensity, whereas external control beliefs did not show an association. Hence, believing in having control over health appears to be helpful when undergoing a chronic pain treatment.

For health care providers it may be important to explore, and if needed to strengthen their patients' beliefs of control over their health to optimally profit from their treatment.
Correspondence: Elian ZuercherHuerlimann

Division of Psychosomatic Medicine,

Department of Neurology, Inselspital,

Bern University Hospital, Bern $\mathrm{CH}-30 \mathrm{IO}$,

Switzerland

Tel +4l 3l 6328362

Email elian.zuercher@psychologie.ch 


\section{Introduction}

Chronic pain is a highly prevalent condition in the general population that may cause considerable impairment, disability and reduced quality of life. ${ }^{1}$ From a biopsychosocial perspective, chronic pain presents in the context of a complex and multifaceted interplay of a patient's physiological, emotional, cognitive, behavioral and sociocultural factors. ${ }^{2}$ In consequence, multimodal and interdisciplinary treatments are considered the method of choice in the treatment and management of chronic pain. ${ }^{3,4}$ Psychological interventions have been shown to increase self-management and coping-strategies, and to reduce disability as well as emotional distress in chronic pain patients. ${ }^{2}$

Beliefs about controlling personal health have been found to predict resilience and adjustment in physically ill patients. ${ }^{5}$ Personal control beliefs may be internal or external. Internal health locus of control (I-HLOC) is the extent to which subjects attribute control over their health to their own behavior. The extent to which someone attributes control over his or her health to external factors can either be social or fatalistic. Whereas social-external HLOC (SE-HLOC) sees powerful others such as medical experts to be in control of one's health, fatalistic-external HLOC (FE-HLOC) attributes the own health status to factors of chance, luck or fate. Consequently, the construct of HLOC can be measured on three dimensions: internal, social-external, and fatalistic external HLOC. ${ }^{6}$

In a systematic review, I-HLOC was generally associated with resilience in patients with physical diseases. ${ }^{5}$ For patients with low back pain, a moderating effect for I-HLOC on the paindepression association was found. ${ }^{7}$ Furthermore, back pain patients with a high I-HLOC profited from a multidisciplinary treatment to a higher degree regarding lifting-capacity scores, ${ }^{8}$ and patients with chronic pain with a higher I-HLOC had lower depression scores than patients with a higher FE-HLOC. ${ }^{9}$ However, findings regarding external HLOC are heterogeneous: Whereas a strong FE-HLOC was found to be negatively associated with quality of life in most studies, the predictive value of the SE-HLOC seems to vary according to ethnicity and age. ${ }^{5,9}$ In a recent study with hand surgery patients, patients with higher pain at study enrollment and lower social-external HLOC experienced stronger pain at 4-month follow-up. ${ }^{10}$ However, it is unclear whether attributing control to powerful others is equally beneficial in a different treatment setting such as a multidisciplinary treatment of chronic pain.

The aim of the present study was to examine whether dimensions of HLOC measured at pre-treatment predict selfrated pain intensity in chronic pain inpatients after a personalized multidisciplinary inpatient treatment. Given that improving self-management and coping strategies are considered to be key elements in the treatment of chronic pain patients, ${ }^{2}$ we hypothesized that a higher I-HLOC is predictive of lower pain intensity in chronic pain patients, adjusted for pretreatment pain intensity, gender, age and pain duration.

\section{Materials and methods}

In a tertiary psychosomatic university clinic in Switzerland, data was routinely assessed at the beginning of the hospitalization and at discharge of a multidisciplinary chronic pain treatment program. The present study includes data from 225 consecutive inpatients with chronic pain conditions hospitalized between 2011 and 2014 in its retrospective analyses. Patients were considered eligible when meeting the diagnostic criteria for either somatoform pain disorder (F45.4, ICD-10) or suffering from a comorbid chronic pain condition with a mental or behavioral disorder (F00-99, ICD-10) confirmed by a clinician.

The average treatment duration was routinely limited to around 3-4 weeks. As a standard, all patients received medical and pharmacological interventions, weekly individual psychotherapy, physical therapy, as well as group based progressive muscle relaxation. Individual therapists were selected according to availability. Within this general framework, the treatment was tailored to the patients' personal needs as much as possible. Patients provided written informed consent and the study was conducted in accordance with the Declaration of Helsinki. Ethical approval was obtained by the applicable ethics committee (Kantonale Ethikkommision für die Forschung, Bern, Switzerland, 2018-00467).

The patients' gender, age and pain duration were documented at intake. In order to measure the changes in pain symptoms over the course of treatment, patients rated their mean pain intensity over the last week using a numeric rating scale (NRS, range $0-10$ ) at beginning and end of treatment.

To assess the three dimensions of HLOC: (I-HLOC, SEHLOC and FE-HLOC) at pretreatment, patients completed the German Health and Illness Related Control Beliefs Questionnaire $(\mathrm{KKG})^{11}$ which was developed on the base of the Multidimensional Health Locus of Control Scale (MHLOC). ${ }^{6}$ The KKG assesses the three dimensions with 21 items and demonstrated acceptable to good internal consistency of the respective scale (Cronbach's alphas for the internal scale: 0.81 ; for the social-external scale: 0.65 ; for the fatalistic-external scale: 0.80). Participants completed the paper-pencil questionnaires supported by research assistants.

To analyze the prediction of treatment outcome by HLOC, hierarchical regression analyses were conducted 
using IBM SPSS 22. For each dimension of the HLOC, a separate analysis was conducted. Age, gender and pain duration were entered as control variables in the first block, as well as the autoregressive control variable pain intensity pretreatment. In the second block either I-HLOC, SEHLOC or FE-HLOC was entered. $P$-values $<0.05$ were considered significant. There was no collinearity for the independent variables (tolerance $>0.10$ and VIF $<10$ ).

\section{Results}

Patient characteristics are shown in Table 1. The mean age was 48.2 years, and $54.2 \%$ were women. The median pain duration reported by patients was 4 years and 3.7 months. The average treatment duration was 29.3 days $(\mathrm{SD}=8.2$, range $=14-71$ ). From pre- to posttreatment, there was a significant decline in the average pain intensity (NRS) ( $t=7.68, p<0.001$, Cohen's $d=0.504)$. On average, the sample's pain intensity decreased by $1.07(\mathrm{SD}=2.1)$. Initial pain intensity was not significantly correlated with any of the

Table I Characteristics of patients and descriptive values $(n=225)$

\begin{tabular}{|c|c|c|c|}
\hline & Mean (SD) & Range & Frequency \\
\hline Age (years) & $48.2(12.8)$ & $16-80$ & \\
\hline $\begin{array}{c}\text { Gender } \\
\text { Female } \\
\text { Male }\end{array}$ & & & $\begin{array}{l}54.2 \%(n=122) \\
45.8 \%(n=103)\end{array}$ \\
\hline $\begin{array}{l}\text { Pain duration } \\
\begin{array}{l}0-3 \text { months } \\
4-6 \text { months } \\
7-11 \text { months } \\
1-5 \text { years } \\
6-10 \text { years } \\
>10 \text { years }\end{array}\end{array}$ & & & $\begin{array}{l}5.3 \%(n=12) \\
7.1 \%(n=16) \\
6.7 \%(n=15) \\
37.3 \%(n=84) \\
12.9 \%(n=29) \\
30.7 \%(n=69)\end{array}$ \\
\hline $\begin{array}{l}\text { Pain intensity (NRS) } \\
\text { pretreatment }\end{array}$ & $6.4(2.0)$ & $0-10$ & \\
\hline $\begin{array}{l}\text { Pain intensity (NRS) } \\
\text { posttreatment }\end{array}$ & $5.4(2.1)$ & $0-10$ & \\
\hline $\begin{array}{l}\text { Internal health locus } \\
\text { of control (I-HLOC) } \\
\text { Social-external health } \\
\text { locus of control (SE- } \\
\text { HLOC) } \\
\text { Fatalistic-external } \\
\text { health locus of control } \\
\text { (FE-HLOC) }\end{array}$ & $\begin{array}{l}24.4(5.7) \\
23.5(5.2)\end{array}$ & $\begin{array}{l}10-39 \\
9-36\end{array}$ & \\
\hline
\end{tabular}

HLOC dimensions (I-HLOC $r=0.032, p=0.636$; SE-HLOC $r=0.126, p=0.059$; FE-HLOC $r=-0.015, p=0.820$ ).

The hierarchical linear regression analyses were conducted separately, testing effects of each dimension of HLOC on pain intensity (NRS) posttreatment while controlling for age, gender, pain duration, and pretreatment pain intensity. Table 2 presents results examining the predictive value of I-HLOC. Greater I-HLOC predicted lower levels of pain intensity at posttreatment $(\beta=$ $-0.151, t=-2.562, p<0.05)$, explaining $1.9 \%$ of the variance, above and beyond the control variables gender and pain duration, including pre-treatment pain intensity. Noticeably, the control variable age turns significant $(\beta=-0.118, t=-1.983, p<0.05)$ in step 2 when IHLOC is included in the model, whereas age does not appear as a significant predictor in step 1 .

Neither SE-HLOC $(\beta=-0.034, t=-0.556, p=0.579)$ nor FE-HLOC ( $\beta=0.095, t=1.623, p=0.106)$ emerged as significant predictors in their analyses.

\section{Discussion}

Pain intensity was significantly decreased in chronic pain patients following a multidisciplinary treatment program, and patients with a high I-HLOC before treatment reached a greater reduction in pain intensity after treatment compared to patients with low I-HLOC. In contrast, relinquishing control to powerful others or fate was not associated with significant pain relief.

Considering the extensive median pain duration, it is worth highlighting that I-HLOC emerged as a predictor of reductions in pain intensity after a comparably short average treatment duration of four weeks.

The present results concur with previous studies about I-HLOC predicting a reduction in depressive symptoms, increased resilience, and improved physical functioning in low back pain patients. ${ }^{5,7-9}$ Our study suggests that the positive impact of high 1-HLOC in chronic pain patients may not be restricted to mental health outcomes but also affect pain relief after chronic pain treatment. The result that age was a significant predictor in interaction with I-HLOC, but not alone, suggests that fostering internal control beliefs may be particularly promising regarding better pain relief in older patients.

The finding of SE-HLOC not predicting pain relief appears to be in contrast to an earlier finding in handsurgery patients, in whom lower levels of SE-HLOC at 
Table 2 Hierarchical regression analysis predicting pain intensity (NRS) at posttreatment

\begin{tabular}{|c|c|c|c|c|c|}
\hline & \multicolumn{5}{|c|}{ Pain intensity (NRS) posttreatment (step $2: R^{2}=0.256 ;$ adj. $R^{2}=0.239$ ) } \\
\hline & B & SE & $\boldsymbol{\beta}$ & $\mathbf{T}$ & $\mathbf{R}^{2} \mathrm{ch}$ \\
\hline Step I & & & & & $0.220 * * *$ \\
\hline Age & -0.018 & 0.010 & -0.109 & -1.803 & \\
\hline Gender & 0.178 & 0.244 & 0.043 & 0.728 & \\
\hline Pain duration & 0.094 & 0.086 & 0.065 & 1.088 & \\
\hline Pain intensity pretreatment & $0.502 * * *$ & 0.062 & $0.480 * * *$ & $8.054 * * *$ & \\
\hline Step 2 & & & & & $0.019 * * *$ \\
\hline Age & $-0.019 *$ & 0.010 & $-0.118^{*}$ & $-1.983 *$ & \\
\hline Gender & 0.245 & 0.243 & 0.059 & 1.012 & \\
\hline Pain duration & 0.091 & 0.085 & 0.063 & 1.069 & \\
\hline Pain intensity pretreatment & $0.509 * * *$ & 0.062 & $0.487 * * *$ & $8.263 * * *$ & \\
\hline Internal health locus of control (I-HLOC) & $-0.054^{*}$ & 0.021 & $-0.15 I^{*}$ & $-2.562 *$ & \\
\hline
\end{tabular}

Notes: $n=225$. $*_{p}<0.05, * * *<<0.001$.

Abbreviations: NRS, Numeric rating scale; $S E$, standard error; $R^{2} c h, R^{2}$ change.

enrollment predicted worse pain outcomes after 4 months follow-up. ${ }^{10}$ However, a patient in a personalized multimodal interdisciplinary treatment of chronic pain may be faced with a wider range of opportunities, challenges and choices than in hand-surgical treatment. The latter is more structured and more depending on the involved medical experts, whereas a multimodal interdisciplinary treatment setting is more individualized. In addition all single interventions demand the patient's participation and motivation to a high degree. Furthermore, a lower number of medical experts may be involved in the surgical setting, to whom the social-external attribution is more clearly linked to. These factors might explain why the internal attribution of control weighs heavier in the complex and individualized treatment setting of chronic pain.

The FE-HLOC not predicting an improvement in pain intensity, is also in line with the results in the previous literature. $^{5,9}$

Limitations of our study are a lack of assessment of ethnicity and missing long-term follow-up to test for effects of I-HLOC on treatment outcome beyond the hospitalization period.

In conclusion, the findings of our study stress the importance of internal beliefs of health control in the multidisciplinary treatment of chronic pain patients. If our results can be replicated, health care providers may assess control beliefs at the outset of a multidisciplinary treatment of chronic pain and pay special attention to patients with low levels of I-HLOC and consider interventions to increase the level of internal control beliefs in terms of improved self- and pain management.

\section{Disclosure}

Prof. Dr. Roland von Känel reports personal fees from Vifor AG Switzerland, outside the submitted work. The authors report no other conflicts of interest in this work.

\section{References}

1. Grabe HJ, Meyer C, Hapke U, et al. Somatoform pain disorder in the general population. Psychother Psychosom. 2003;72(2):88-94. doi:10.1159/000068681

2. Roditi D, Robinson ME. The role of psychological interventions in the management of patients with chronic pain. Psychol Res Behav Manag. 2011;4:41-49. doi:10.2147/PRBM.S15375

3. Grandhe R, Souzdalnitski D, Gritsenko K. New chronic pain treatments in the outpatient setting: review article. Curr Pain Headache Rep. 2016;20(5):33. doi:10.1007/s11916-016-0563-y

4. Stanos S. Focused review of interdisciplinary pain rehabilitation programs for chronic pain management. Curr Pain Headache Rep. 2012;16(2):147-152. doi:10.1007/s11916-012-0252-4

5. Stewart DE, Yuen T. A systematic review of resilience in the physically ill. Psychosomatics. 2011;52(3):199-209. doi:10.1016/j.psym.2011.01.036

6. Wallston KA, Wallston BS, DeVellis R. Development of the Multidimensional health locus of control (MHLC) scales. Health Educ Monogr. 1978;6(2):160-170.

7. Campbell P, Hope K, Dunn KM. The pain, depression, disability pathway in those with low back pain: A moderation analysis of health locus of control. J Pain Res. 2017;10:2331-2339. doi:10.2147/JPR.S139445

8. Keedy NH, Keffala VJ, Altmaier EM, Chen JJ. Health locus of control and self-efficacy predict back pain rehabilitation outcomes. Iowa Orthop J. 2014;34:158-165.

9. Wong HJ, Anitescu M. The role of health locus of control in evaluating depression and other comorbidities in patients with chronic pain conditions, a cross-sectional study. Pain Pract. 2016/2017;17(1):52-61. doi:10.1111/papr.2017.17.issue-1

10. Stewart JA, Aebischer V, Egloff N, et al. The role of health locus of control in pain intensity outcome of conservatively and operatively treated hand surgery patients. Int J Behav Med. 2018;25(3):374-379. doi:10.1007/s12529-018-9713-4

11. Lohaus A, Schmitt GM. Fragebogen Zur Erhebung Von Kontrollüberzeugungen $\mathrm{Zu}$ Krankheit Und Gesundheit (KKG). Handanweisung: Verlag für Psychologie Hogrefe; 1989. 


\section{Publish your work in this journal}

The Journal of Pain Research is an international, peer reviewed, open access, online journal that welcomes laboratory and clinical findings in the fields of pain research and the prevention and management of pain. Original research, reviews, symposium reports, hypothesis formation and commentaries are all considered for publication. The manuscript management system is completely online and includes a very quick and fair peer-review system, which is all easy to use. Visit http:// www.dovepress.com/testimonials.php to read real quotes from published authors.

Submit your manuscript here: https://www.dovepress.com/journal-of-pain-research-journal 